Evaluación del texto

\title{
«Cali, Capital deportiva, \\ ciudad cívica y sede del narcotráfico: tres \\ representaciones sociales urbanas»
}

\author{
escrito por Camilo Adolfo Mayor \\ (Comunicador social y Magíster en Sociología \\ de la Universidad del Valle)
}

Por Alejandro Ulloa

(ausa52@hotmail.com)

Profesor Titular

Escuela de Comunicación Social, Facultad de Artes Integradas, Universidad del Valle.

Cali, Colombia. 


\section{ntroducción}

El texto presentado por Camilo Mayor como propuesta editorial para su publicación, es el resultado de una investigación sociológica sobre las imágenes públicas de esta ciudad, en cuanto representaciones colectivas. Tales representaciones no son producto de la estrategia del "City marketing», creada para construir imágenes positivas de una urbe y promoverla ante el mundo. Son ante todo construcciones discursivas creadas en un proceso en el que han participado diversos actores con funciones específicas.

\section{Fundamentación teórica}

Para su análisis el autor apela al concepto sociológico de representación con el fin de examinar tres imágenes que ha proyectado Cali durante los últimos 40 años como ciudad deportiva, cívica y sede del narcotráfico. Teóricamente se ha privilegiado el concepto de representación colectiva de Emile Durkheim por el estatuto sociológico que posee en tanto categoría explicativa de las ciencias sociales. Además de haberse asimilado a otras nociones como imaginario, o ideología, en algunos estudios, el concepto de representación se ha utilizado de manera descontextualizada y por fuera de las dinámicas sociales, según lo reseña el autor en este trabajo. De ahí que su propósito sea asumirlo como un referente fundamental asociado con un proceso histórico durante el cual se construyen las tres clases de representación mencionadas acerca de Cali, documentadas mediante la indagación empírica correspondiente. En la discusión del concepto, Camilo Mayor alude a varios autores que lo han teorizado. Empieza por Durkheim para quien «tras el símbolo hay que encontrar la realidad que representa y que le da su verdadero significado» teniendo en cuenta que las representaciones hacen parte de las relaciones sociales. 0 como lo afirma el autor «...una representación social, lejos de ser una instancia separada de las relaciones sociales, no sólo hace parte de éstas, sino que, incluso, contribuye a su formación...»

Cita también a Roger Chartier para quien «la representación es el instrumento de un conocimiento mediato que hace ver un objeto ausente al sustituirlo por una 'imagen' capaz de volverlo a la memoria y de 'pintarlo' tal cual es». A Moscovici, quien define la representación social como «una modalidad particular del conocimiento, cuya función es la elaboración de los comportamientos y la comunicación entre los individuos. La representación es un corpus organizado de conocimientos y una de las actividades psíquicas gracias a las cuales los hombres hacen inteligible la realidad física y social, se integran en un grupo o en una relación cotidiana de intercambios, liberan los poderes de su imaginación». Una vez decantado el concepto, el autor se pregunta ¿»Cómo se produce y reproduce una representación social?» ¿»Puede ser la ciudad objeto de representaciones sociales?» « $i$ Qué se entiende por representación social de una ciudad»? Con base en la definición dada, el autor concluye que «debe entenderse como representación social de una ciudad la estructura simbólica mediante la cual es posible acceder a una forma de conocimiento de un espacio urbano determinado; y que, a través de su representación, es posible la aprehensión y comprensión de la ciudad como realidad concreta...» 
Para responder la primera pregunta Mayor acude a Moscovici quien diferencia dos procesos: «objetivación y anclaje». El primero "consiste en 'hacer real un objeto", es decir «asimilar la idea a la materia». «El segundo consiste en la inserción de dicho objeto en un sistema de significaciones...» Por otro lado, alude también a Beriain quien habla de la institucionalización y la ritualización de las representaciones como formas prácticas para fijarlas y arraigarlas en la conciencia colectiva con el fin de «fijar reglas de conducta a través de permisos y prohibiciones, organizar y legitimar o no las relaciones sociales».

\section{Aspectos metodológicos}

Metodológicamente se tomó como fuente principal el diario El País de esta ciudad, «el cual fue consultado en sus diferentes secciones informativas» para

recopilar los datos a través de una ficha en la que se consignó la información pertinente. Como parte de la metodología se seleccionaron varios eventos de gran magnitud, entre ellos Los VI Juegos Panamericanos realizados en 1971 para estudiar la imagen deportiva y cívica; la visita del papa Juan Pablo II en 1985 y otros acontecimientos relativos al civismo en los 80's; la celebración de los 450 años de fundación de Cali en 1986, y las campañas de «limpieza social» ejecutadas durante esta misma década. Finalmente, los acontecimientos relacionados con el Cartel de Cali, en los años 90, su apogeo y desmoronamiento, como referente para examinar la imagen asociada con el narcotráfico.

Así mismo, se hizo una caracterización de varios actores sociales determinantes en la producción de las representaciones, para evaluar su papel, las funciones desempeñadas y las diferencias entre ellos: En este caso se destacan tres agentes que objetivan y anclan las representaciones: las instituciones políticas, los grupos de establecidos (las élites dominantes) y los medios de comunicación masiva, en particular el diario $\mathrm{El}$ PAís, tomado como fuente de información primordial para la investigación. El autor nos recuerda cómo la prensa, y particularmente este periódico, nace como una extensión del poder político y económico regional, para ganar más o consolidarlo por otras vías.

\section{Los Actores}

El País, fue un decidido promotor de campañas en torno al deporte desde que se eligió a Cali como sede de los VI juegos panamericanos (y no sólo para su realización, como se deduce de la investigación de Camilo Mayor). También fue un actor dinámico durante la década de los ochenta en la producción de una imagen cívica, cuando impulsó jornadas de enlucimiento con motivo de la venida del papa y luego para los 450 años de fundación de la ciudad. Mayor diferencia este papel cumplido por el periódico para la representación del deporte y el civismo, del que ejerció para la representación de Cali como ciudad del narcotráfico en la década siguiente, cuando «el diario se caracterizó por cierto mutismo y recelo en el tratamiento de la información y cuando la ciudad había cambiado y el diario también...» (pág. 56)

Dentro de la metodología se registró la información siguiendo la secuencia descrita sobre la construcción de las representaciones sociales (objetivación, anclaje y ritualización) y las funciones de éstas (fijar la realidad e interpretarla; organizar, controlar y legitimar las relaciones sociales). Todo ello a partir de los tres agentes sociales identificados como dinamizadores de dichos procesos y funciones. Puesto que tales agentes no operaron de igual forma siempre, ni la información fue lineal, se determinó hacer el análisis tomando tres momentos en torno al evento seleccionado; antes, durante y después del mismo. Así por ejemplo, no hubo acciones de ritualización de la imagen deportiva por parte de las instituciones políticas, pero sí por parte de los grupos establecidos y del periódico El País.

\section{Las representaciones: «Cali capital deportiva de América»}

A pesar de las limitaciones o la precariedad del deporte local y nacional, esta consigna se «impuso» gracias a la conjugación de intereses deportivos y extradeportivos que tuvieron en los medios masivos una caja de resonancia para promover los juegos panamericanos como un motivo y una oportunidad para «modernizar» la ciudad y aliviar las tensiones sociales, convirtiéndola en una urbe «civilizada y moderna». Pero los tres actores que participan en la construcción de la imagen deportiva actúan diferente y con distintos objetivos, según los diversos momentos que se presentan en torno al evento deportivo. 
A pesar de toda la parafernalia montada, la realidad contradecía la «buena imagen», pues ni los resultados deportivos fueron los mejores, ni las desigualdades estructurales desaparecieron, ni el comportamiento ciudadano derivado de las mismas se transformó. Como concluye el propio autor «Los tres actores analizados no consolidaron una ritualización de la imagen deportiva, que lograra la cohesión pregonada y anhelada.... Los tres agentes no tuvieron una clara actuación en el proceso de ritualización de la representación social que conllevara a la unidad de los diversos grupos sociales a pesar de las diferencias, las cuales, en cambio, se hicieron más notorias. Según la información recolectada por el autor, hubo reventa de boletas « a la vista de las autoridades y con la timorata complacencia de la policía»; «también se denunciaron abusos de los taxistas en el cobro de las tarifas». Y los juegos, además de ser «el milagro de Cali», también «provocaron el alza en el costo de vida durante su realización, mientras que las obras que se adelantaron no disminuyeron la taza de desempleo, pues también se contrató personal de otros departamentos...Y contra el aludido buen comportamiento del público, alguna queja reportaron los diarios de Estados Unidos según los cuales «en los juegos se oía 'Yankis go home' y se victoreaban a los cubanos...” (pag. 81) Todos estos hechos junto a otros igualmente significativos contradicen la cosmética que maquillaba la ciudad como una ciudad cívica y deportiva.

Según Mayor, con ello se iniciaba el declive de la representación deportiva de Cali» (pág. 83). «En la fase posterior a los Juegos Panamericanos sucedió cierta «desestructuración» de los procesos y fases de producción y reproducción de la representación social deportiva. Obviamente el evento había concluido y la discordancia entre la realidad y la imagen no permitía dar mayor sentido a una idea sin piso a tierra» (pág. 83). A nuestro juicio, a pesar de la desestructuración de los procesos de construcción de la imagen deportiva, ésta persistió en los medios y en el imaginario colectivo al punto que fue revivida en varios momentos significativos. El autor pasa por alto tres acontecimientos importantes que permiten reactivar el imaginario de Cali como capital deportiva, así sea coyunturalmente. Ellos son: el mundial de natación realizado en esta ciudad en 1975 (4 años después de los Panamericanos) en el que se consagró una figura mundial heroica como Mark Spitz con mucha resonancia mediática en la prensa escrita y la televisión que se estaba masificando en Colombia. Luego, el mundial de basketball en 1981- 82 cuando se retomó la imagen deportiva. Y entre los dos eventos la gran campaña del deportivo Cali, finalista de la copa Libertadores de 1978, con todo lo que movilizaba el fútbol, siendo esta la primera vez que un equipo colombiano llegaba a la máxima instancia de este deporte a nivel internacional. Estos eventos le daban aire a la representación deportiva que siguió siendo explotada por diferentes actores, cada que se presentaba la oportunidad. El hecho de que El País no siga enfatizando en el tema, según los hallazgos del autor, no puede tomarse como indicador suficiente de la finalización de la imagen deportiva para decir que ya no seguía funcionando. Dicha representación continuaba latente en el imaginario colectivo y se activaba permanentemente por otras vías mediáticas como la radio. Esta es una de las consecuencias de la investigación centrada en un solo medio de comunicación, aislado de los otros, o al menos de otro como la radio con el que suele trabajar en «llave» de manera complementaria en campañas y eventos específicos. Si bien la radio no era el objetivo de la investigación, tal vez por la inexistencia de archivos sonoros, debe reconocerse su importancia, aún mayor que la del periódico, no sólo por tratarse de varias emisoras a la vez sino por su alcance e impacto masivo, a todas luces superior al de un diario. Por eso no es procedente concluir que la imagen deportiva culminó con los juegos panamericanos como se afirma en el texto. (págs 84-87). Si para el periódico perdió importancia, no lo fue para la ciudad y su gente incluidos otros medios de información masiva.

\section{¿Cali, ciudad cívica?}

Este interrogante indaga por la correspondencia entre la realidad social de Cali en un periodo determinado y la representación social cívica de la ciudad que emergió entonces, con el fin de describir y confirmar o no dicha relación. Por otro lado, se cuestiona si efectivamente eso que se llamó civismo y que dio nombre a la ciudad, en verdad lo fue, lo cual implica revisar el concepto de civismo y observar cómo fue aplicado en la ciudad. Para ello el autor diferencia entre civismo, proceso civilizatorio y civilidad.

Aunque a nuestro juicio la emergencia de la imagen deportiva es anterior a la imagen de civismo, ambas se consolidan con los VI juegos Panamericanos cuando la élite empresarial y 
política se unen para crear y promover una representación de Cali como ciudad deportiva y cívica al mismo tiempo. De ahí la interpelación permanente a la ciudadanía por todos los medios de comunicación existentes en aquella época - y no sólo por el diario El País - para embellecer la ciudad (maquillarla), mientras se ocultaban las desigualdades sociales, la corrupción bipartidista y el abuso del poder. A además de promover una imagen de la ciudad de la cual, imaginariamente, «todos hacen parte», se ejerce una forma de control sobre la población apelando a consignas como el aseo, la limpieza, el buen comportamiento, el establecimiento del orden.

Al rastrear los antecedentes de la imagen de civismo, el autor se remonta a los comienzos del siglo XX y encuentra referencias a las buenas costumbres, a la regulación de la conducta y a un modelo de comportamiento ejemplar que debe ser asumido por sectores de la población, convocada mediante un discurso «modernizador» y civilizatorio.de la ciudad. Pero aquella fue una convocatoria diferente a la de los Juegos Panamericanos, no sólo porque se pretendía controlar el desorden del pueblo en los lugares públicos y vigilar la moral, sino porque para 1971 la ciudad era objeto de la mirada internacional, frente a la cual era necesario mostrar una imagen de modernización y orden social. De ahí que el civismo se conciba como un mecanismo de control ante la presión y el conflicto social de la época caracterizada por una confrontación de clases en el contexto de «lucha revolucionaria y antiimperialista» dentro y fuera del país. Creo que estos aspectos, inadvertidos en la obra de Mayor, hacen parte de las condiciones en que se diseñaron las campañas como producto de una intención deliberada de las élites. En efecto, estas concitan el concurso de los actores involucrados para el análisis y de la ciudadanía en general. Algunos sectores acogieron con entusiasmo la iniciativa de amor por la ciudad y aunque implementaron las prácticas de limpieza, «la realidad estructural» siguió predominando por encima de las imágenes que la maquillaban. Si la ciudad estaba escindida (y continúa estándolo) entre un sector normalizado y establecido, frente a sectores anómicos y marginalizados, el discurso del civismo servía como puente para alentar una pretendida unificación que terminó siendo ilusoria, pero que a la postre le sirvió a las élites para su legitimación, sobre todo cuando implementaron campañas y prácticas filantrópicas «en beneficio de los pobres», que reforzaban el llamado al buen comportamiento, el respeto al orden y la urbanidad.

Con respecto a la imagen de civismo, o la representación de Cali como ciudad cívica, hay un segundo momento que corresponde al trisesquicentenario de la fundación de Cali, cuando cumplió 450 años en 1986. La celebración de este aniversario estuvo precedida y acompañada de jornadas de limpieza y aseo, labores de enlucimiento, pavimentación de vías y «obras sociales» mediante diversas campañas que enarbolaban el «civismo» como patrón a seguir cuyo impacto en los medios de comunicación fue decisivo.

En este tópico el autor concluye afirmando que «el papel del medio de comunicación objetivando la realidad social de Cali, pero sobre todo, anclándola (o institucionalizándola) fue regular y dominante a lo largo de esta fase. Es decir que El País tuvo una destacada participación en dos de los procesos de formación de la imagen cívica de Cali, con sus respectivas y consecuentes funciones» al desplegar información permanente sobre los trabajos realizados con ocasión de la visita papal y los 450 años de Santiago de Cali. En otras palabras, el civismo se implementaba como una expresión colectiva y ferviente, pero canalizada, en tanto forma de control social. Según el autor, «el diario coadyuvó a objetivar la imagen cívica de Cali y a asimilarla a la realidad de la ciudad para lograr la identificación de los ciudadanos» con la imagen promocionada. «Tras objetivar la idea del civismo, el diario desempeñó un papel clave en el proceso de institucionalización de dicha representación social, dando significado al mundo objetivado, haciéndolo funcional y comprensible al conjunto de la sociedad, guiando y orientando conductas, en procura de organizar y controlar las relaciones sociales, función propia del proceso de anclaje de la representación social» (pág. 102). Esta fue una manera cómo los establecidos, representados en un periódico, y a través de su opinión, participaron en el proceso de anclaje de la representación cívica de Cali no sólo para fijar normas de conducta, sino mediante «la invitación a participar, a colectivizar ese mundo cívico, que diluía diferencias...» (pág. 107)

Por su parte, las instituciones políticas, especialmente la Administración Municipal, otro de los actores estudiados, participó en la elaboración de la representación cívica de la ciudad, «tanto en el proceso de objetivación, 
como en el de institucionalización». Su labor «favoreció también el anclaje de una representación social cívica de la ciudad, en función de organizar y controlar las relaciones sociales» en conjunto con los demás agentes. (pág. 109).

Camilo Mayor pone en evidencia la simultaneidad de dos procesos paralelos como son la «cosmética cívica» ya descrita, reforzada mediante el accionar filantrópico de las élites - los establecidos - que aparecen cual nobles redentores frente a los pobres; y al mismo tiempo, la intensificación de la violencia organizada dirigida contra marginados y todos aquellos que podrían considerarse como peligrosos para el orden social. Retomando los lemas de las campañas de aseo urbano, se llevaron a cabo sistemáticas jornadas de «limpieza social» que alcanzaron incluso a grupos guerrilleros como el M19 instalados en el barrio Siloé. A través de la campaña «Cali limpia, Cali linda en navidad» (que Mayor no menciona) se realizó una verdadera guerra para acabar con dicha organización político militar en la que murieron muchos civiles inocentes, durante la toma del barrio por las fuerzas de seguridad del estado.

No obstante esa omisión significativa ( creo que debería incorporarse al análisis porque hace parte del mismo proceso) Camilo Mayor explica cómo, a finales de esa década, la estrecha relación entre la dirigencia económica (especialmente del sector industrial) y la política (reflejada en el gobierno municipal), se dio de manera distinta. De acuerdo con él, «Muy a pesar del sentido filantrópico que en ese entonces afloraba incitando al civismo, expresado en la proliferación de organismos no gubernamentales orientados a programas sociales, se presentó una gradual separación entre la política local y la clase empresarial...»(pág. 45)

La recomposición de los grupos de poder económico se produjo, entre otras razones, gracias a dos nuevas circunstancias: de un lado el giro dado por las élites en la orientación de la política económica de Cali como una ciudad de servicios; y por otro, con la emergencia de grupos vinculados con el narcotráfico que aparecieron en la escena política a competir por el poder «y/o sostener alianzas con las viejas élites». La clase emergente no era un sector establecido, pero penetró los sectores establecidos de antaño, para parecerse a ellos y tener el control político de la ciudad.

\section{La narco imagen de Cali}

Un poco después de consolidadas las representaciones deportiva y cívica empieza a configurarse la representación asociada con el narcotráfico. Aunque el autor concentra su análisis en la década del 90 con motivo de la persecución al cartel de Cali, la verdad es que esta imagen se fragua desde comienzos de los 80 y tiene momentos álgidos a mediados de la década cuando se declara la guerra con el cartel de Medellín y hacia 1988 cuando el departamento de estado norteamericano saca a la luz pública en todos los medios de comunicación, pero sobretodo en la televisión, las fotos de la organización criminal a la que se propone perseguir, como lo ha hecho hasta la actualidad. Debe destacarse este acontecimiento, que Camilo Mayor pasa por alto, tal vez involuntariamente, pero que fue definitivo como proyección internacional de esta «nueva» representación, (la llamo «el estigma global»), frente a la cual el jefe de los capos se manifestó diciendo: «El cartel es un invento de la Dea».

Ante dos representaciones positivas como la del deporte y el civismo, la del narcotráfico constituye una imagen altamente negativa que, a mi juicio, pone en crisis las anteriores, no sólo porque se opone a ellas en tanto valor negativo en el ámbito de las representaciones, sino porque las prácticas sociales sobre las que se fundamenta el narcotráfico son contrarias a la civilidad y el civismo. En otras palabras, tanto en la esfera de las imágenes como en «la realidad», el narcotráfico contradice toda pretensión «cívica», pues los comportamientos propios de la «cultura traqueta» son, por principio, transgresores del orden social establecido, aunque la cultura narco no se menciona en este trabajo.

A pesar de que estas consideraciones (la puesta en crisis de una identidad urbana) no son tematizadas por el autor, lo que la investigación de Camilo Mayor revela es otra lógica en la construcción de las representaciones asociadas al narcotráfico, al describir algunos de los eventos que la originaron. Al respecto afirma lo siguiente: «resulta pertinente observar de qué manera se impuso el narcotráfico como forma de representación de Cali. Si representar socialmente es producir sentido social habría que develar cómo una actividad ilegal, propensa a la violencia, a la formación de redes comerciales internacionales y clandestinas, y al 
enriquecimiento súbito, produjo un sentido social urbano».

Para atender la pregunta, Mayor alude a diferentes estudios sobre el narcotráfico en Colombia que coinciden en señalar cierto grado de tolerancia y permisividad por parte de la sociedad colombiana - y no sólo la dirigencia política - con el negocio ilícito desde finales de los años 70 cuando comienza a ser visible en el país. Y aunque el autor no lo menciona, es conveniente aclarar que el contubernio continuó hasta entrado el siglo XXI, según lo revelan las investigaciones jurídicas sobre la parapolítica en los últimos 5 años. Pero como lo que se está analizando es la creación de una narco imagen vinculada con la ciudad - que terminó siendo asociada con todo el país a nivel internacional Camilo Mayor resalta la ambigüedad que históricamente ha caracterizado a distintos sectores de la sociedad caleña - y colombiana, para el caso nacional - al fluctuar entre la aceptación y el rechazo de los narcotraficantes. Gracias al poder del dinero y a su intimidación por la violencia, estos lograron seducir, permear y penetrar todos los niveles del orden social, así como todas las clases, sectores de clase, partidos políticos, instituciones del estado y amplios sectores de la población civil, de manera directa 0 indirecta.

Siendo así, la creación de esta representación urbana de Cali, aunque no fue objetivada por el periódico local, ni por las instituciones políticas, ni los establecidos, sí contó con una base social subjetiva que sabía "cómo eran las cosas», desde antes que la imagen se anclara por la prensa internacional cuyas informaciones ratificaban lo que la sociedad caleña ya conocía por diferentes vías. Esta aclaración es necesaria porque para el autor, «tratándose de una representación negativa de la ciudad, ésta no se propició desde el interior de la sociedad local, sino, muy posiblemente, desde el exterior, bien nacional o internacionalmente, aunque ya hay una pista y es aquella que parte de los señalamientos dados por las autoridades estadounidenses sobre varias ciudades colombianas, entre ellas Cali.» (pág. 148). A pesar de desconocer esa subjetivación colectiva, el autor admite «...que el primer agente promotor de una imagen de Cali como ciudad del narcotráfico, fueron los propios narcotraficantes, provenientes de sectores no establecidos y, dada su actividad ilegal que da cuenta, entre otras cosas, de la resolución violenta de sus conflictos...» (pág. 156). Esto significa que, en comparación con las representaciones anteriores, las agentes dinamizadores en la objetivación y anclaje de las mismas no cumplieron, para la narco-imagen la función que sí habían desempeñado antes. Para el autor, «brillaron por su ausencia las instituciones políticas locales que otrora habían apoyado y promovido la formación de representaciones sociales de la ciudad a través de eventos deportivos o cumpleaños centenarios... Por ejemplo, la Alcaldía de Cali o la Gobernación del Valle permanecieron invisibles frente al acontecer urbano relacionado con el narcotráfico y a la formación de esta «narco-imagen» de Cali, y ello según que estas instituciones políticas locales no fueron precisamente las que promovieron esta representación , como tampoco hicieron público su rechazo» (pág. 151). En la investigación no se observa claramente que los tres agentes analizados traten de «objetivar, institucionalizar y mucho menos ritualizar esta representación- negativa - de Cali».

Además de responsabilizar a los narcos como los primeros promotores de la imagen estigma, el autor afirma que en este caso fueron «agentes internacionales (haciendo hincapié en los Estados Unidos ) tanto políticos como periodísticos, los que primordialmente apalancaron dicha representación social desde el proceso de anclaje o institucionalización, el cual, se recuerda, consiste en la inserción de dicho objeto, para este caso, el narcotráfico, en un sistema de significaciones que busca legitimar procedimientos y conseguir la movilización de masas, organizando y controlando las relaciones sociales» (pág. 162). Y luego añade: "con el señalamiento desde lo global a lo local se objetivaba una representación social ciertamente negativa, pero además con la posición sancionatoria, se buscaba organizar y fijar reglas de conducta» para el colectivo (pág. 163). La construcción discursiva de esta narco imagen se intensificó después de la muerte de Pablo Escobar y la derrota del cartel de Medellín a manos de sus enemigos. Y si bien la prensa norteamericana llevó la voz cantante durante este periodo, el diario local hizo eco de sus señalamientos, citando o reproduciendo partes de la información, según el análisis de Camilo Mayor.

Para terminar, creo pertinente anotar que el seguimiento y la búsqueda de datos en el periódico El País es exhaustivo, lo mismo que el procesamiento de la información y el análisis que desarrolla el autor, en concordancia con los 
objetivos propuestos y la metodología adoptada. Sin embargo, abordar un problema tan complejo la construcción de las representaciones - a partir de un solo medio de comunicación tomado como fuente y referencia para examinar la función desempeñada, no deja de tener inconvenientes cuando se tiene la certeza de que en ese proceso intervinieron activamente otros medios de comunicación con mayor impacto social como las emisoras locales. La dificultad para acceder a los archivos sonoros de la época, si acaso existen, imponen una limitación al proceso investigativo; por eso mismo las conclusiones a que se llega tendrán siempre un valor relativo y una validez limitada, que merecen una revisión del autor con miras a la publicación del texto. Pretender conclusiones más universales con respecto a la creación de las representaciones estudiadas es una ilusión que desvirtúa los logros alcanzados en este importante trabajo realizado por Camilo Mayor. Pero como no se puede evaluar lo que la investigación no se propuso hacer, sino lo que hizo, destaco, entre otros méritos, la perspectiva crítica con que enfrenta, desde la sociología, los lugares comunes de un discurso que ha hecho carrera no sólo en los medios de comunicación sino en las administraciones municipales, empeñadas en alimentar una representación social de la ciudad, tan precaria como la realidad en que se sustenta. Explicar los mecanismos por medio de los cuales se han producido estas imágenes, es una valiosa contribución para la ciudad que debe escuchar, como un llamado de atención, los estudios de esta naturaleza, escasos pero necesarios cuando se pretende fortalecer procesos democráticos participativos y construcción de ciudadanía.

Las anteriores son razones suficientes para avalar la publicación de este trabajo como un primer paso en esa dirección. 